\title{
Effect of positive end-expiratory pressure on intrapulmonary shunt at different levels of fractional inspired oxygen
}

\author{
A OLIVEN, U TAITELMAN, F ZVEIBIL, AND S BURSZTEIN
}

From the Intensive Care Department, Rambam Medical Centre, Haifa, Israel

ABSTRACT In 10 patients undergoing ventilation, venous admixture was measured at different values of positive end-expiratory pressure (PEEP). The measurements were performed at the level of fractional inspired oxygen $\left(\mathrm{FIO}_{2}\right)$ at which each patient was ventilated, and at $\mathrm{FIO}_{2}=1$. In patients ventilated at $\mathrm{FiO}_{2}$ between 0.21 and 0.3 venous admixture was not modified by PEEP, while in patients ventilated with $\mathrm{FIO}_{2}$ between 0.4 and 0.6 , venous admixture decreased significantly $(\mathrm{p}<0.01)$. With $\mathrm{FIO}_{2}=1$, increased PEEP produced a reduction in venous admixture in all cases ( $p<0.05$ ). These observations suggest that in patients similar to ours, PEEP does not reduce venous admixture at low levels of $\mathrm{FIO}_{2}(0 \cdot 21-0 \cdot 3)$, and the observed reduction with $\mathrm{PEEP}$ at $\mathrm{FIO}_{2}=1$ may be misinterpreted.

In patients with acute respiratory failure, positive end-expiratory pressure (PEEP) has been said to reduce pulmonary venous admixture and improve arterial blood oxygenation. ${ }^{1-3}$ The efficiency of PEEP can thus be evaluated by its influence on venous admixture. Most studies dealing with venous admixture are performed at $\mathrm{FIO}_{2}=1$. However, modifications of $\mathrm{FIO}_{2}$ are known to alter shunt values. ${ }^{4}$ It is not clear whether the beneficial effect of PEEP on pulmonary shunting at lower values of $\mathrm{FIO}_{2}$ is the same as at $\mathrm{FIO}_{2}=1$. In this report we describe the results of investigations carried out on patients submitted to various levels of PEEP at different values of $\mathrm{FIO}_{2}$.

\section{Patients and methods}

The study was conducted on 10 adult patients ventilated with a Bennett MA-1 respirator for various reasons (table 1). Venous admixture was calculated without PEEP, and again at 5, 10, and $15 \mathrm{~cm} \mathrm{H} \mathrm{H}_{2} \mathrm{O}$ PEEP, after a 15-minute period of equilibrium at each PEEP level. For each patient measurements were performed at the $\mathrm{FIO}_{2}$ as determined by the clinical status, and repeated at $\mathrm{FIO}_{2}=1$. The patients were sedated,

Address for reprint requests: $\mathrm{Dr} A$ Oliven, Department of Medicine "B". Rothschild University Hospital, POB 4940, Ila:fa, Israel. and vital signs and minute volume were repeatedly checked, in order to confirm steady state conditions. Blood samples were drawn simultaneously into heparinised glass syringes from an indwelling arterial line and from a pulmonary artery catheter (Edwards Model 7FD). The venous admixture was calculated from the shunt equation:

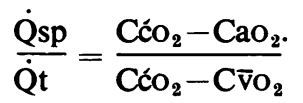

Where: $\mathrm{CaO}_{2}=1 \cdot 39 \cdot \mathrm{Hb} \cdot \mathrm{Sat}_{\mathrm{a}} \mathrm{O}_{2}+0.0031 \mathrm{PaO}_{2}$

$$
\mathrm{Cvo}_{2}=1 \cdot 39 \cdot \mathrm{Hb} \cdot \mathrm{Sat}_{\mathrm{v}} \mathrm{O}_{2}+0.0031 \mathrm{PvO}_{2}
$$

For $\mathrm{Cc}_{2} \mathrm{O}_{2}$ the alveolar air equation was used:

$$
\begin{aligned}
\mathrm{PAO}_{2}=\mathrm{FIO}_{2}\left(\mathrm{P}_{\mathrm{Bar}}-\mathrm{PH}_{2} \mathrm{o}\right) & \\
& -\mathrm{PACO}_{2}\left(\mathrm{FIO}_{2}+\left(1-\mathrm{FIO}_{2}\right) / \mathrm{RQ}\right)
\end{aligned}
$$

and the respiratory quotient (RQ) was calculated for patients ventilated with $\mathrm{FrO}_{2}$ between 0.21 and 0.3 according to:

$$
\mathrm{RQ}=\frac{\mathrm{FECO}_{2}\left(1-\mathrm{FIO}_{2}\right)}{\mathrm{FIO}_{2}\left(1-\mathrm{FEO}_{2}-\mathrm{FECO}_{2}\right)-\mathrm{FEO}_{2}}
$$

For respiratory gases oxygen concentrations were measured using a paramagnetic oxygen analyser (Servomex OA-250) and carbon dioxide concentrations were determined with the Godart Capnograph. Blood gases and $\mathrm{pH}$ were measured with the Astrup Radiometer apparatus. Oxygen saturation was calculated according to the Gomez formula. ${ }^{7}$ All calculations, including 
Table 1 Effect of PEEP on venous admixture at indicated FIO: and at FIO: = I

\begin{tabular}{|c|c|c|c|c|c|c|c|c|c|c|c|c|}
\hline \multirow[t]{2}{*}{ Diagnostic } & \multirow[t]{2}{*}{$\operatorname{Sex}$} & \multirow{2}{*}{$\begin{array}{l}\text { Age } \\
(y r)\end{array}$} & \multirow[t]{2}{*}{$\mathrm{F}_{\mathrm{IO}_{2}}$} & \multicolumn{4}{|c|}{$P E E P\left(\mathrm{~cm} \mathrm{H} \mathrm{H}_{2} \mathrm{O}\right)$} & \multirow[t]{2}{*}{$\mathrm{F}_{\mathrm{IO}}$} & \multicolumn{4}{|c|}{$P E E P(\mathrm{~cm} \mathrm{H}, O)$} \\
\hline & & & & 0 & 5 & 10 & 15 & & 0 & 5 & 10 & 15 \\
\hline Multiple trauma, sepsis & $\mathbf{M}$ & 46 & $0 \cdot 21$ & $0 \cdot 26$ & 0.28 & 0.25 & 0.26 & 1 & 0.25 & $0 \cdot 24$ & $0 \cdot 23$ & 0.21 \\
\hline Multiple trauma, uraemia & $\mathbf{F}$ & 64 & $\mathbf{0 . 2 1}$ & 0.33 & $\mathbf{0 . 3 3}$ & 0.37 & 0.39 & 1 & $0 \cdot 30$ & 0.32 & $0 \cdot 30$ & 0.3 \\
\hline Chronic obstructive airways disease, sepsis & $\mathbf{F}$ & 74 & $0 \cdot 21$ & $0 \cdot 18$ & 0.20 & $0 \cdot 15$ & $0 \cdot 17$ & 1 & $0 \cdot 19$ & $0 \cdot 13$ & $0 \cdot 15$ & 0.15 \\
\hline Brain contusion, pneumonia & $\mathbf{M}$ & 32 & 0.29 & 0.28 & 0.36 & $0 \cdot 31$ & $0 \cdot 39$ & 1 & $0 \cdot 20$ & $0 \cdot 17$ & 0.20 & $\mathbf{0} \cdot \mathbf{2}$ \\
\hline Burns $85 \%$ & $\mathbf{F}$ & 40 & 0.30 & 0.36 & 0.34 & 0.32 & $0 \cdot 31$ & 1 & $0 \cdot 27$ & $0 \cdot 24$ & $0 \cdot 17$ & 0.19 \\
\hline Chest trauma & $\mathbf{F}$ & 32 & 0.40 & $0 \cdot 17$ & $0 \cdot 20$ & 0.12 & $0 \cdot 10$ & 1 & $0 \cdot 24$ & $0 \cdot 24$ & 0.26 & 0.2 \\
\hline Brain and lung contusion & $\mathbf{M}$ & 64 & 0.40 & $0 \cdot 32$ & $0 \cdot 27$ & 0.35 & 0.29 & 1 & 0.30 & $0 \cdot 28$ & 0.25 & $0 \cdot 18$ \\
\hline Peritonitis, sepsis & $\mathbf{M}$ & 78 & 0.41 & $0 \cdot 34$ & 0.29 & 0.29 & $0 \cdot 32$ & 1 & 0.28 & 0.23 & $0 \cdot 21$ & $0 \cdot 2$ \\
\hline Peritonitis, pneumonia & $\mathbf{F}$ & 72 & 0.47 & 0.33 & 0.38 & 0.36 & 0.21 & 1 & 0.36 & 0.35 & 0.26 & 0.2 \\
\hline Pneumonia, cerebrovascular accident & $\mathbf{M}$ & 72 & 0.60 & $0 \cdot 38$ & $0 \cdot 36$ & 0.35 & $0 \cdot 34$ & $i$ & $0 \cdot 34$ & 0.39 & $0 \cdot 36$ & $0 \cdot 3$ \\
\hline
\end{tabular}

statistics, were performed on a PDP 11/05 computer.

\section{Results}

The 10 patients were divided into two groups according to the $\mathrm{FIO}_{2}$ indicated by their clinical condition. The first group was ventilated at $\mathrm{FIO}_{2}$ between 0.21 and 0.3 , and the second group at $\mathrm{FiO}_{2}$ between 0.4 and 0.6 . Table 1 contains a summary of the shunt values in both groups as measured at the patient's required $\mathrm{FIO}_{2}$ and at $\mathrm{FIO}_{2}=1$.

In fig 1 the influence of PEEP (from 0 to $15 \mathrm{~cm} \mathrm{H}_{2} \mathrm{O}$ ) on $\mathrm{PaO}_{2}, \mathrm{CaCO}_{2}, \mathrm{a}-\mathrm{vDO}_{2}$, and intrapulmonary shunt is compared during ventilation with $\mathrm{FiO}_{2}$ between 0.21 and 0.3 and at $\mathrm{FIO}_{2}=1$. In the first instance PEEP has little influence on these values. In the same patients however, the same procedure, but at $\mathrm{FIO}_{2}=1$, resulted in a significant decrease in the intrapulmonary shunt $(\mathrm{p}<0.05)$.

Figure 2 depicts the results in the five other patients. In this group increased PEEP induced a significant increase of $\mathrm{PaO}_{2}$ and $\mathrm{CaO}_{2}$ $(\mathrm{p}<0.01)$, and a significant decrease in shunt $(\mathrm{p}<0.01)$ during ventilation with $\mathrm{FiO}_{2}=0.4-0.6$, as well as during ventilation with $\mathrm{FIO}_{2}$ equal to unity (increase in $\mathrm{PaO}_{2}$ and $\mathrm{CaO}_{2}, \mathrm{p}<0.05$, and decrease in shunt $\mathrm{p}<0.05$ ). A slight increase of a-v $\mathrm{Do}_{2}$ in these patients was not significant at either level of $\mathrm{FiO}_{2}$.

\section{Discussion}

In 1942, Berggren suggested a method of calculating intrapulmonary venous admixture by the inhalation of pure oxygen, ${ }^{89}$ and thus two of the problems associated with shunt determination were eliminated. By using an increased oxygen concentration, it is possible to avoid the shunt effect caused by the perfusion of partially ventilated alveoli. ${ }^{4}$ This method thus allows the determination of the "true shunt", which is caused by an admixture of venous blood from non-ventilated parts of the lung. The second problem is the difficulty in measuring or calculating the alveolar oxygen concentration required for intrapulmonary shunt calculations This can be measured using a fast response oxygen analyser, or calculated using the alveolañ air equation. Since fast response oxygẹ

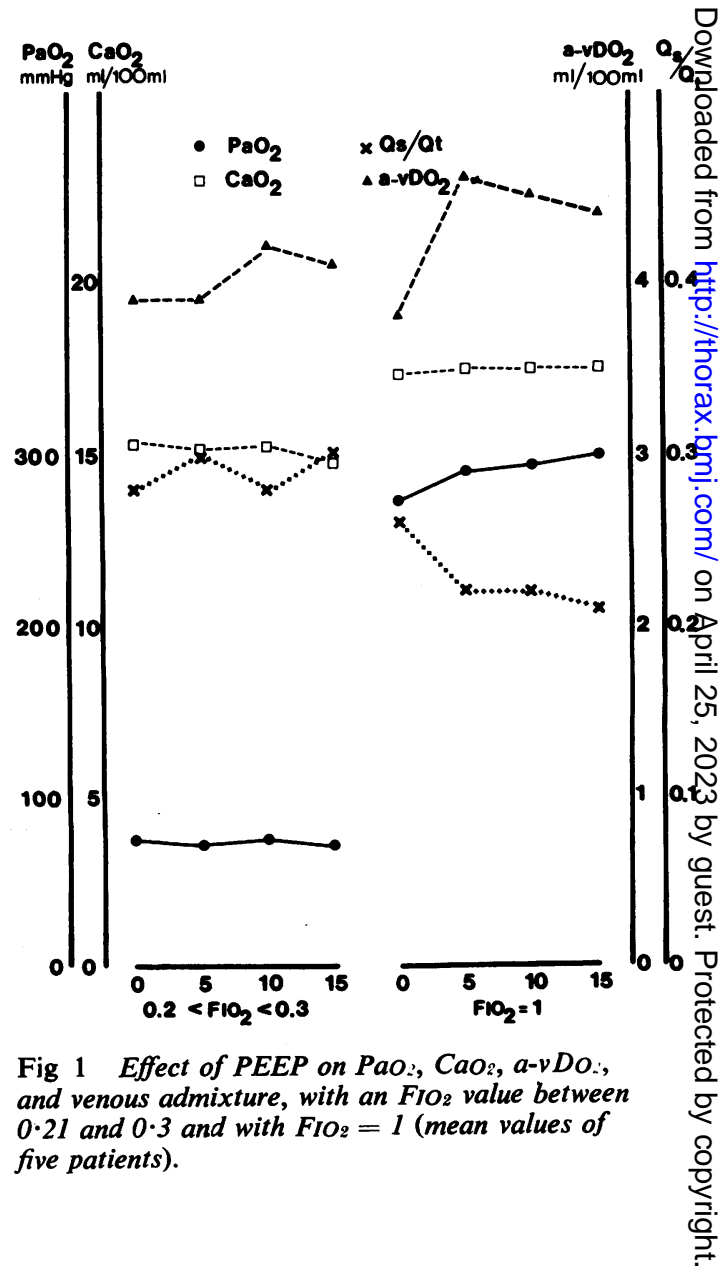




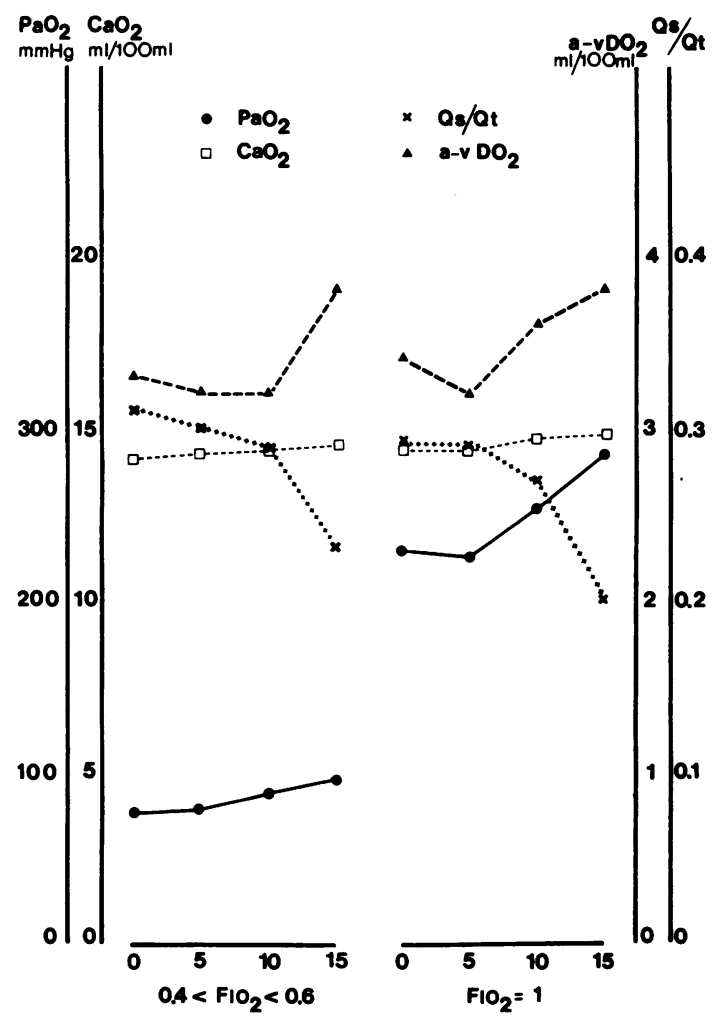

Fig 2 Effect of PEEP on Pao, CaO, a-vDo, and venous admixture, with a FIO: value between 0.4 and $0 \cdot 6$, and with FIO: $=1$ mean values of five patients).

analysers are not always available and the resolution of the alveolar air equation requires the determination of $\mathrm{FEO}_{2}$ and $\mathrm{FECO}_{2}$ the use of $\mathrm{FIO}_{2}=1$ will greatly simplify calculation for the venous admixture. Indeed, at $\mathrm{FIO}_{2}=1$ the "correction factor" $\left(\mathrm{FIO}_{2}+\left(1-\mathrm{FIO}_{2}\right) / \mathrm{RQ}\right)$ is cancelled to unity, and the alveolar air equation becomes: $\quad \mathrm{PAO}_{2}-\mathrm{FIO}_{2} \quad\left(\mathrm{P}_{\mathrm{Bar}}-\mathrm{PH}_{2} \mathrm{O}\right)-\mathrm{PcaO}_{2}$. Inhalation of pure oxygen is therefore widely used during venous admixture measurements for clinical and scientific purposes. ${ }^{10-15}$ However, it is now well documented that high $\mathrm{FrO}_{2}$ influences the pulmonary shunt by itself. Several workers found an increase in the pulmonary shunt after high $\mathrm{FIO}_{2}$ administration, explained by a reduction in the functional residual capacity (FRC) ${ }^{1316}$ because of absorption atelectasis. ${ }^{10} 11$ 16-20 This inverse correlation between FRC and venous admixture has been demonstrated previously. ${ }^{21} 22$ Otherwise, the shunt may decrease when $\mathrm{FIO}_{2}$ increases. ${ }^{13}$ If it is obvious that variations of $\mathrm{FIO}_{2}$ modify the value of the shunt, it is also evident that measurements of venous admixture should be performed at the particular $\mathrm{FiO}_{2}$ inhaled by the patient, as indicated by the clinical status. The clinical value of this form of shunt calculation is also preferable, as it takes into account changes in ventilation-perfusion disturbances when the $V / Q$ ratio is greater than zero. ${ }^{23}{ }^{24}$ The difficulty in calculating the venous admixture with values of $\mathrm{FIO}_{2}$ lower than unity does not justify shunt measurements with pure oxygen. Moreover, we found that usually another method can be used to eliminate the "correcting factor" for simplifying the alveolar air equation. When $\mathrm{FrO}_{2}$ is higher than 0.3 , one can assume the RQ value as constant and equal to unity, as usual variations of the $R Q$ values cannot modify the calculated shunt. We calculated the venous admixture at the patient's $\mathrm{FIO}_{2}$ with $\mathrm{RQ}$ values varying from 0.6 to 1.4 , and it became apparent that only in patients ventilated with an $\mathrm{FIO}_{2}=0.21$ did modification of the RQ values influence the calculated venous admixture, while for all $\mathrm{FIO}_{2}$ values higher than 0.29 venous admixture varied only slightly (table 2). For these reasons, in patients with an enriched concentration of oxygen, which is usually the case, one may assume for purposes of calculation that the RQ is equal to unity, and eliminate the correction factor $\left(\mathrm{FIO}_{2}+\left(1-\mathrm{FIO}_{2}\right) / 1=\right)$. However, in patients breathing room air, or air slightly enriched with oxygen, the shunt has to be calculated using the real RQ values.

Most of the studies on the influence of PEEP on venous admixture were performed on patients ventilated with $\mathrm{FIO}_{2}=1$. With few exceptions, ${ }^{25} 26$ a decrease in shunt value was usually found with PEEP, ${ }^{2} 2$ 27-33 correlated with an increased FRC. ${ }^{2}{ }^{31-34}$ Therefore, venous admixture is considered as one of the main factors in evaluating "optimal PEEP". ${ }^{29}$ Considering the influence of $\mathrm{FIO}_{2}$ on the calculated pulmonary shunt found

Table 2 Influence of respiratory quotient values on the calculated shunt at different levels of FIO. Patients were divided according to their FIO', and mean pulmonary shunt of each group was calculated, using the measured blood gas values and assuming values of $R Q$ varying from 0.6 to 0.4

\begin{tabular}{|c|c|c|c|c|c|c|}
\hline FIC 2 & $R Q$ & 0.5 & 0.8 & $I$ & $1 \cdot 2$ & 1.4 \\
\hline $\begin{array}{l}0.21 \\
0.29-0.30 \\
0.40-0.41 \\
0.47-0.60\end{array}$ & & $\begin{array}{l}0.23 \\
0.31 \\
0.24 \\
0.34\end{array}$ & $\begin{array}{l}0.26 \\
0.32 \\
0.25 \\
0.34\end{array}$ & $\begin{array}{l}0.28 \\
0.32 \\
0.25 \\
0.34\end{array}$ & $\begin{array}{l}0.29 \\
0.32 \\
0.25 \\
0.34\end{array}$ & $\begin{array}{l}0 \cdot 29 \\
0 \cdot 32 \\
0 \cdot 25 \\
0 \cdot 34\end{array}$ \\
\hline
\end{tabular}


in our patients, it is questionable, however, whether the observed influence of PEEP on venous admixture at $\mathrm{FIO}_{2}$ equal to unity reflects the effect of PEEP at lower levels of $\mathrm{FiO}_{2}$.

In this study PEEP had no influence on venous admixture at low levels of $\mathrm{FIO}_{2}$ $(0 \cdot 21-0 \cdot 3)$, suggesting that PEEP has little value in patients who can be ventilated at this Fio. The significant reduction in venous admixture produced by PEEP in the same patients at $\mathrm{FIO}_{2}=1$ demonstrates that, in order to evaluate the real effect of PEEP on venous admixture as a guide to therapy, measurements have to be carried out at the patient's required $\mathrm{FiO}_{2}$. At higher levels of $\mathrm{FIO}_{2}$ the influence of FIO. variations on the PEEP effect is apparently less important; the reduction in venous admixture obtained with PEEP in patients ventilated at $\mathrm{FIO}_{2}=0.4-0.6$ as similar to that observed when they were ventilated at $\mathrm{FIO}_{2}=1$.

We have shown that the influence of PEEP in our patients varied with the value of $\mathrm{FIO}_{2}$, and that its effect on pulmonary shunt was absent when $\mathrm{FIO}_{2}$ was lower than $\mathrm{C} \cdot 3$. Assuming that PEEP increases FRC, while high Fio. decreases it, the beneficial effect of PEEP at high $\mathrm{FIO}_{2}$ could be partially explained by the reduction of this side effect of the high $\mathrm{FiO}_{2}$, but further ventilation-perfusion alterations as well as variations in pulmonary resistance and pulmonary fluid content must be considered. It is possible that for special situations, as in pulmonary oedema or drowning, PEEP could be effective at low $\mathrm{FIO}_{2}$, but none of our patients had these conditions.

In summary, our results suggest that PEEP does not influence the intrapulmonary shunt at low levels of $\mathrm{FiO}_{2}(0 \cdot 21-0 \cdot 3)$. When $\mathrm{FiO}_{2}$ is greater than 0.3 the calculation of venous admixture can be simplified by neglecting the "correction factor" of the alveolar air equation.

\section{References}

1 King EG, Jones RL, Patakas DA. Evaluation of positive end-expiratory pressure therapy in adult respiratory distress syndrome. Can Anaesth Soc J 1973; 20:546-58.

2 Ashbaugh DG, Petty TL. Positive end-expiratory pressure: physiology, indications and contraindications. J Thorac Cardiovasc Surg 1973; 65: 165-70.

3 Gilston A. The effect of PEEP on arterial oxygenation. Intensive Care Med 1977; 3:267-71.

4 Georg J, Hornum I, Mellemgaard K. The mechanism of hypoxaemia after laparotomy. Thorax 1967; 22:382-6.
5 Pontoppidan H, Bushnell LS. Respiratory therapy for convalescing surgical patients with chronic lung disease. Clin Anaesth 1967; 1:101-26.

6 West JB. Ventilation/blood flow and gas ex $\frac{\overline{\bar{S}}}{\overline{5}}$

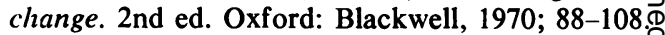

7 Gomez DM. Considerations of oxygen-hemo globin equilibrium in the physiological state. $A m^{\text {s }}$ J Physiol 1961; 200:135-42.

8 Berggren $\mathbf{S}$. The oxygen deficit of arterial bloodcaused by non-ventilating parts of the lung. Actaw Physiol Scand 1942; 4: suppl 11:1-92.

9 Farhi LE, Rahn H. A theoretical analysis of thex alveolar arterial $\mathrm{O}_{2}$ difference with special refer- $-\omega$ ence to the distribution effect. J Appl Physiolw 1955; 7:699-702.

10 Suter PM, Fairly HB, Schlobohm RM. The response of lung volume and pulmonary per-은 fusion to short periods of $100 \%$ oxygen ventila tion in acute respiratory failure. Crit Care Medz $1974 ; 2: 43-4$.

11 Finley TN, Lenfant C, Haab P, Piiper J, Rahı̊ $H$. Venous admixture in the pulmonary circula $\vec{\bullet}$ tion of anaesthetised dogs. J Appl Physiol 1960\% 15:418-24.

12 Velasquez T, Farhi LE. Changes in complianceo during pressure breathing. Fed Proc 1961; 20 427.

13 McAslan TC, Matjasko-Chiu J, Turney SZ Cowley RA. Influence of inhalation of $100 \% \bar{D}$ oxygen on intrapulmonary shunt in severely traumatised patients. J Trauma 1973; 13:811-21.

14 Weil, HM, Shubin H. Critical care medicine handbook. New York: John Kolen Inc., 1974贵 30-4.

15 Wagner PD, Larvuso RB, Uhl RR, West JB. Continuous distribution of ventilation perfusion ratio in normal subjects breathing air and $100 \%$ oxygen. J Clin Invest 1974; 54:54-68.

16 Dery R, Pelletier J, Jaques A, Clavet M, Honde J. Alveolar collapse induced by denitrogenation. Can Anaesth Soc J 1965; 12:531-44.

17 Dale AW, Rahn H. Rate of gas absorption during atelectasis. Am J Physiol 1952; 170:606-15.

18 Rahn H, Farhi LE. Gaseous environment ando atelectasis. Fed Proc 1963; 22:1035-41.

19 Burger EJ, Mead J. Static properties of lung after oxygen exposure. J Appl Physiol 1969; 27:191-7 N

20 Suwa K, Corbin FH, Schanble JF et al. PAO $\mathrm{PaO}_{2}$ relationship for the entire therapeutic ${ }^{\omega}$ range of oxygen in acute respiratory failure Abstracts of scientific papers. American Societyo of Anaesthesiologists' Annual Meeting, 1972: 123-4.

21 Bursztein S, Glaser P. Etude synchronique de laD regulation de l'equilibre acido-basique dans les? suites de la chirurgie abdominale. Milan: Ganassini, 1970; 122-9.

22 Powers SR, Mannal R, Neclerio MJ. Physiologico consequences of positive end expiratory pressure (PEEP) ventilation. Ann Surg 1973; 178:265-72. 
23 Nunn JF. Applied respiratory physiology. London: Butterworth, 1969; 344.

24 Hobelman CF, Smith DE, Virgilio RW, Shapiro AR, Peters RM. Hemodynamic alteration with positive end expiratory pressure: the pulmonary vasculature. J Trauma 1975; 15:951-8.

25 Modell JH. Ventilation/perfusion change during mechanical ventilation. Dis Chest 1969; 55: 447-51.

26 Neclerio MT, Custead W, Marr C, Powers SR Jr. Compartmental analysis of nitrogen washout curves by computer. In: Proc 1st Annual New England Bioengineering Conference 1973; 1: 217-26.

27 Gregory GA, Kitterman JA, Phibbs RH, Tooley WH, Hamilton WK. Treatment of idiopathic respiratory distress syndrome with continuous positive airway pressure. $N$ Eng J Med 1971; 284:1333-40.

28 Carter GL, Downs JB, Dannemiller FJ. "Hyper" end-respiratory pressure in the treatment of adult respiratory insufficiency. A case report. Anaesth Analg 1975; 54:31-4.
29 Kirby RR, Downs JB, Vivetta JM et al. High level positive end expiratory pressure (PEEP) in acute respiratory insufficiency. Chest 1975; 67: 156-63.

30 Kumar A, Elake KJ, Geffin B et al. Continuous positive pressure ventilation in acute respiratory failure: effect on lung function. $N \mathrm{Engl} \mathrm{J} \mathrm{Med}$ 1970; 283:1430-6.

31 McMahon SM, Helprin GM, Sieker HD. Positive end expiratory airway pressure in severe arterial hypoxemia. Am Rev Respir Dis 1973; 108:526-35.

32 Sugerman HJ, Rogers RM, Miller LD. Positive end expiratory pressure (PEEP): indications and physiologic considerations. Chest 1972; 62:865948.

33 Downs JB, Klein EF, Modell JH. The effect of incremental PEEP on $\mathrm{PaO}_{2}$ in patients with respiratory failure. Anaesth Analg 1973; 52:210-15.

34 McIntyre RW, Laws AK, Ramachandran PR. Positive expiratory pressure plateau. Improved gas exchange during mechanical ventilation. Can Anaesth Soc J 1969; 16:477-86. 